\title{
Análise espaço temporal da qualidade da água dos rios Peruípe, Itanhém e Jucuruçu, Bahia
}

Timeline analysis of river water quality from Peruípe, Itanhém and Jucuruçu rivers, Bahia

\author{
R. V. Quinelato; E. da S. Farias*; J. M. S. de Brito; W. A. Virgens; L. C. Pires \\ Programa de Pós Graduação em Ciências e Tecnologias Ambientais, Universidade Federal do Sul da Bahia, 4581 - \\ 000, Porto Seguro - BA, Brasil \\ *emillyfarias10@hotmail.com
}

(Recebido em 21 de janeiro de 2020; aceito em 07 de julho de 2020)

\begin{abstract}
As bacias dos rios Peruípe, Itanhém e Jucuruçu têm grande relevância para o abastecimento de diversos munícipios do Extremo Sul da Bahia. Portanto, monitorar e avaliar a qualidade dessas águas é fundamental para a gestão sustentável dos recursos hídricos dessa região. Nesse contexto, o presente trabalho objetivou avaliar a qualidade da água desses rios em 12 pontos de monitoramento situados em 8 munícipios. Para tanto, utilizou-se dados extraídos do Instituto do Meio Ambiente e Recursos Hídricos do Estado da Bahia (INEMA), dentre eles coliformes termotolerantes, clorofila- $a$, nitrato, nitrogênio, temperatura, salinidade, alcalinidade, sólidos dissolvidos totais, turbidez, potencial hidrogeniônico, oxigênio dissolvido, demanda bioquímica de oxigênio, demanda química de oxigênio, fósforo total e amônia, bem como o Índice de Qualidade da Água (IQA) entre 2009 e 2019. Os resultados obtidos foram comparados aos limites estabelecidos na Resolução CONAMA N 357 de 2005, tanto para as águas doces Classe 2 quanto salobras Classe 1 e faixas de IQA. Resultados de coliformes termotolerantes, sólidos dissolvidos totais, turbidez, potencial hidrogeniônico, oxigênio dissolvido, demanda bioquímica de oxigênio, fósforo total e amônia extrapolaram os padrões estabelecidos na resolução CONAMA $N^{\circ} 357 / 2005$, estando diretamente relacionados ao uso e ocupação do solo, sem o devido acompanhamento de infraestrutura básica e ausência de um esgotamento sanitário que atenda adequadamente às comunidades localizadas próximas às bacias hidrográficas. Os resultados do IQA nas três bacias variaram entre 56,3 e 72,1, o que indica que as águas podem ser classificadas como qualidade boa, apesar das alterações em alguns parâmetros.

Palavras-chave: qualidade das águas, recursos hídricos, poluição.
\end{abstract}

The Peruípe, Itanhém and Jucuruçu river basins have great relevance for the supply of several municipalities in the extreme south of Bahia. Therefore, monitoring and evaluating the quality of these waters is essential for the sustainable management of water resources in this region. In this context, the present study aimed to assess the water quality of these rivers at 12 monitoring points located in 8 municipalities. To this end, data extracted from the Institute of Environment and Water Resources of the State of Bahia (INEMA) were used, including thermotolerant coliforms, chlorophyll-a, nitrate, nitrogen, temperature, salinity, alkalinity, total dissolved solids, turbidity, potential hydrogen, dissolved oxygen, biochemical oxygen demand, chemical oxygen demand, total phosphorus and ammonia, as well as the Water Quality Index (IQA) between 2009 and 2019. The results obtained were compared to the limits established in CONAMA Resolution $\mathrm{N}^{\circ} 357$ of 2005 , both for Class 2 freshwater and Class 1 brackish waters and IQA bands. Results of thermotolerant coliforms, total dissolved solids, turbidity, hydrogen potential, dissolved oxygen, biochemical oxygen demand, total phosphorus and ammonia extrapolated the standards established in CONAMA Resolution 357/2005, being directly related to land use and occupation, without the due to the monitoring of basic infrastructure and the absence of sanitary sewage that adequately serves communities located close to river basins. The results of the IQA in the three basins varied between 56.3 and 72.1, which indicates that the waters can be classified as good quality, despite changes in some parameters.

Keywords: water quality, water resources, pollution.

\section{INTRODUÇÃO}

A água é um recurso natural indispensável, tanto para a vida humana, quanto para o meio ambiente e manutenção da biodiversidade presente em todo o planeta, apresentando grande valor econômico e socioambiental. Em virtude disso, a utilização desse recurso natural deve ser de maneira consciente [1]. No entanto, nos últimos anos, foi cada vez mais notória a constatação de bacias hidrográficas degradadas, situação ocasionada principalmente pelo crescimento populacional exacerbado, pela industrialização e pelo uso e ocupação do solo sem o devido 
acompanhamento de infraestrutura básica, dentre elas esgotamento sanitário, limpeza urbana, manejo de resíduos sólidos, drenagem e manejo das águas pluviais [2]. Tais fatores possuem influência direta na quantidade e qualidade dos recursos hídricos em uma bacia hidrográfica, sendo estes determinantes no processo de desenvolvimento socioeconômico local [3,4]. O índice que analisa a qualidade da água de rios e bacias hidrográficas, bem como os parâmetros físico-químicos e microbiológicos, são instrumentos essenciais para a detecção do grau de poluição das águas [5] além de um indicador para que medidas de mitigação ou estratégias para a melhoria da qualidade da água sejam criadas para o controle da poluição [6].

Diante desse cenário, como forma de preservar os recursos hídricos do território, o Brasil conta hoje com diversas legislações que visam assegurar a utilização adequada dos recursos hídricos, dentre elas a Lei N. ${ }^{\circ} 9.433$ de 1997 (institui a Política Nacional de Recursos Hídricos) [7], a Resolução do Conselho Nacional de Meio Ambiente (CONAMA) N. 274 de 2000 (define os critérios para a classificação de águas destinadas à recreação de contato primário) [8], Resolução do CONAMA N. 357 de 2005 (dispõe sobre a classificação dos corpos de água e diretrizes ambientais para o seu enquadramento, bem como estabelece as condições e padrões de lançamento de efluentes, e dá outras providências) [9], Resolução do CONAMA N. ${ }^{\circ} 396$ de 2008 (dispõe sobre a classificação e diretrizes ambientais para o enquadramento das águas subterrâneas e dá outras providências) [10], Resolução do CONAMA N..$^{\circ} 430$ de 2011 (dispõe sobre as condições e padrões de lançamento de efluentes, complementa e altera a Resolução $\mathrm{N}^{\circ}$ 357, de 17 de março de 2005 do CONAMA ) [11], a Norma Brasileira (NBR) N. ${ }^{\circ} 12.212$ de 1992 (dispõe sobre projeto de poço para captação de água subterrânea) [12] e NBR N. ${ }^{\circ} 12.244$ de 1992 (dispõe sobre procedimentos para tamponamento de poços) [13].

Como forma de monitorar e orientar ações de gestão da qualidade da água e planejamento ambiental, e como forma de sintetizar as informações obtidas a partir dos diversos parâmetros físicos, químicos e microbiológicos, determinados nas legislações referentes a qualidade dos recursos hídricos, diversos índices foram elaborados, dentre eles o Índice de Qualidade das Águas (IQA). Esse foi criado em 1970 pela National Sanitation Foundation para avaliar a qualidade da água dos rios e do mar, sendo a Companhia Ambiental do Estado de São Paulo (Cetesb) a pioneira em sua utilização no Brasil, no ano de 1975, com o objetivo de proporcionar informação para população de forma fácil e transparente, sobre a qualidade da água dos locais monitorados. No decorrer dos anos, outros países e estados brasileiros adotaram o IQA, atualmente um dos mais utilizados em estudos para avaliar as condições dos recursos hídricos no Brasil [14].

Quanto à responsabilidade de realizar esse monitoramento e orientação nos rios da união (aqueles que passam por mais de um estado brasileiro ou por territórios estrangeiros) fica a cargo da Agência Nacional de Águas (ANA). Já os rios estaduais e as águas subterrâneas, são de responsabilidade dos Órgãos Ambientais Estaduais. No caso da Bahia, o Instituto do Meio Ambiente e Recursos Hídricos (INEMA), tem entre suas atribuições o dever de fornecer a ANA dados referentes aos recursos hídricos sob sua responsabilidade. Atualmente o INEMA monitora 134 rios, onde analisa cerca de 50 parâmetros de qualidade da água, dentre eles coliformes termotolerantes, potencial hidrogeniônico, oxigênio dissolvido, demanda bioquímica de oxigênio, amônia, sólidos dissolvidos totais e fósforo total [15].

A vista desse cenário, este estudo teve por objetivo analisar os dados de parâmetros da qualidade da água e do IQA, e sua evolução temporal, entre 2009 e 2019, referente aos rios Peruípe, Itanhém e Jucuruçu, localizados no extremo sul da Bahia; identificar áreas prioritárias para o controle da poluição das águas onde a sua qualidade possa estar mais comprometida; e propor ações preventivas e corretivas.

\section{MATERIAL E MÉTODOS}

A área do estudo corresponde às bacias dos rios: Peruípe $\left(4.120,08 \mathrm{~km}^{2}\right)$, Itanhém $(6.379,02$ $\mathrm{km}^{2}$ ) e Jucuruçu $\left(5.978,52 \mathrm{~km}^{2}\right)$. Essas bacias são gerenciadas pelo Comitê de Bacias Hidrográficas dos rios Peruípe, Itanhém e Jucuruçu (CBHPIJ), que faz parte da Região de Planejamento e Gestão das Águas III (RPGA III) do estado da Bahia e abrange os municípios baianos: Alcobaça, Caravelas, Ibirapuã, Itanhém, Lajedão, Medeiros Neto, Teixeira de Freitas, Vereda, Itamaraju, Jucuruçu, Nova Viçosa, Prado, Guaratinga, Itabela e Mucuri, e os municípios mineiros: Águas 
Formosas, Bertópolis, Felisburgo, Fronteira dos Vales, Machacalis, Palmópolis, Rio do Prado, Santa Helena de Minas e Umburatiba. O clima da região é tropical, quente e úmido, com cobertura vegetal de floresta, ou seja, as temperaturas médias mensais são superiores a $18^{\circ} \mathrm{C}$ e não há um só mês com índice pluviométrico médio inferior a $60 \mathrm{~mm}$ [16].

Foram importados do sítio eletrônico do Sistema Estadual de Informações Ambientais e Recursos Hídricos (SEIA) os dados dos parâmetros da qualidade da água e do IQA referentes a Região de Planejamento e Gestão das Águas (RPGA) dos rios em estudo para o período entre 2009 e 2019. As coletas foram realizadas pelo Instituto de Meio Ambiente e Recursos Hídricos (INEMA). Os pontos de coleta, foco desta avaliação, estão distribuídos entre oito municípios da microrregião, sendo eles: Alcobaça, Itamaraju, Jucuruçu, Medeiros Neto, Nova Viçosa, Prado, Teixeira de Freitas e Vereda, classificados entre corpos de Classe 1 (Salobra) e Classe 2 (Doce) (Tabela 1; Figura 1).

As informações sobre a população dos municípios avaliados foram extraídas do sítio eletrônico do Instituto Brasileiro de Geografia e Estatística (IBGE) [17] sobre cidades brasileiras, os referentes ao esgotamento sanitário através do Plano Estadual de Manejo de Águas Pluviais e Esgotamento Sanitário (PEMAPES) [18] e, as atividades econômicas e o uso do solo por meio do Plano Territorial de Desenvolvimento Sustentável e Solidário do Extremo Sul da Bahia (PTDRSS) [19]. A localização dos pontos de coleta é apresentada na Tabela 1.

Tabela 1: Localização dos pontos de coleta de água, código, município e rio no estado da Bahia.

\begin{tabular}{clll}
\hline Ponto & \multicolumn{1}{c}{ Código } & \multicolumn{1}{c}{ Município } & \multicolumn{1}{c}{ Rio } \\
\hline $\mathbf{1}$ & PIJ-ALB-050 & Itanhém & Itanhém/Alcobaça \\
$\mathbf{2}$ & PIJ-ALB-200 & Medeiros Neto & Itanhém/Alcobaça \\
$\mathbf{3}$ & PIJ-ALB-230 & Medeiros Neto & Itanhém/Alcobaça \\
$\mathbf{4}$ & PIJ-ALB-500 & Teixeira de Freitas & Itanhém/Alcobaça \\
$\mathbf{5}$ & PIJ-ALB-700 & Alcobaça & Itanhém/Alcobaça \\
$\mathbf{6}$ & PIJ-ALB-900 & Alcobaça & Itanhém/Alcobaça \\
$\mathbf{7}$ & PIJ-JUC-100 & Jucuruçu & Jucuruçu \\
$\mathbf{8}$ & PIJ-JUC-900 & Prado & Jucuruçu \\
$\mathbf{9}$ & PIJ-JUN-250 & Itamaraju & Jucuruçu \\
$\mathbf{1 0}$ & PIJ-JUN-400 & Itamaraju & Jucuruçu - Norte \\
$\mathbf{1 1}$ & PIJ-JUS-400 & Vereda & Jucuruçu - Sul \\
$\mathbf{1 2}$ & PIJ-PRP-400 & Nova Viçosa & Peruípe - Sul \\
\hline
\end{tabular}




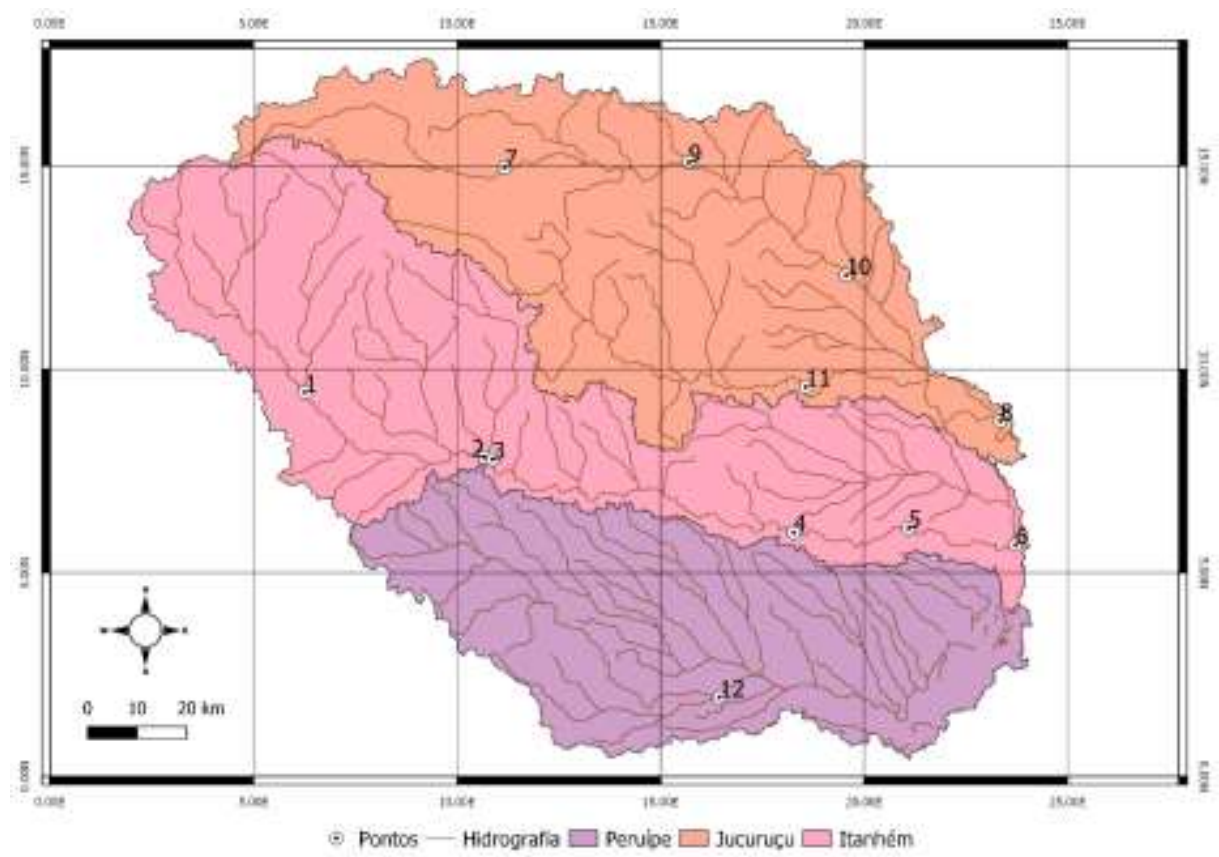

Figura 1: Área de abrangência das bacias dos rios Peruípe, Itanhém e Jucuruçu e localização dos pontos de coleta de água no estado da Bahia. Fonte: Elaborado pelos autores (2020).

Os municípios monitorados, a população total, a porcentagem de domicílios que possuem esgotamento sanitário adequado e as atividades econômicas/uso do solo referente a esses municípios estão apresentadas na Tabela 2.

Tabela 2: População, esgotamento sanitário e atividades econômicas/uso do solo dos municípios.

\begin{tabular}{|c|c|c|c|}
\hline Município & $\begin{array}{l}\text { População } \\
\text { Total } \\
\text { (hab.) }\end{array}$ & $\begin{array}{l}\text { Esgotamento } \\
\text { Sanitário } \\
(\% \text { de } \\
\text { domicílios }) \\
\end{array}$ & Atividades econômicas/uso do solo \\
\hline Alcobaça & 21.271 & $31,7 \%$ & $\begin{array}{l}\text { Situam-se no litoral, tem atividades voltadas } \\
\text { para o turismo, mas a agropecuária e a pesca } \\
\text { são atividades de relevância na economia } \\
\text { local. }\end{array}$ \\
\hline Itamaraju & 63.069 & $55,3 \%$ & Café, cacau, agropecuária. \\
\hline Itanhém & 20.216 & $66,1 \%$ & Agropecuária. \\
\hline Jucuruçu & 10.290 & $35,7 \%$ & Agropecuária. \\
\hline $\begin{array}{l}\text { Medeiros } \\
\text { Neto }\end{array}$ & 21.560 & $35,3 \%$ & Cana-de-açúcar, eucalipto, agropecuária. \\
\hline $\begin{array}{c}\text { Nova } \\
\text { Viçosa }\end{array}$ & 38.556 & $18,3 \%$ & $\begin{array}{l}\text { Situam-se no litoral, as atividades estão } \\
\text { voltadas para pesca, turismo, comércio e } \\
\text { agricultura, principalmente o mamão. }\end{array}$ \\
\hline Prado & 27.627 & $14 \%$ & $\begin{array}{l}\text { Situam-se no litoral, mas mantem } \\
\text { especialmente com a produção de café, além } \\
\text { da pecuária, bens minerais pesca e turismo. }\end{array}$ \\
\hline $\begin{array}{l}\text { Teixeira de } \\
\text { Freitas }\end{array}$ & 138.341 & $75,9 \%$ & $\begin{array}{l}\text { Concentra infraestrutura de serviços e forte } \\
\text { comércio atacadista da região, mas também } \\
\text { agricultura como o mamão e melancia. }\end{array}$ \\
\hline Vereda & 6.800 & $30,4 \%$ & Agropecuária. \\
\hline
\end{tabular}

Fonte: IBGE (2019) [17], Bahia (2011) [18], Bahia (2016) [19].

Inicialmente foram analisados parâmetros microbiológicos (coliformes termotolerantes e clorofila-a); físicos (temperatura, condutividade, sólidos em suspensão, turbidez, sólidos totais 
dissolvidos, sólidos totais e salinidade) e químicos (ortofosfato solúvel, cloreto, potencial hidrogeniônico, demanda química de oxigênio, demanda bioquímica de oxigênio, nitrogênio total, fósforo total, amônia, alcalinidade total, oxigênio dissolvido e porcentagem de saturação de oxigênio dissolvido). No entanto, após análise do banco de dados optou-se pela retirada dos parâmetros ortofosfato solúvel, saturação de oxigênio dissolvido, cloreto e condutividade, por apresentarem falha de mais de $30 \%$ dos dados para cada ano analisado. Os dados foram submetidos à análise descritiva simples para sumarização dos dados e posteriormente aos testes de ShapiroWilk e Kolgomorov-Smirnorf a 1\% de significância, onde não apresentaram distribuição normal, esses então, foram correlacionados através do método de Spearman, sendo consideradas as correlações: fraca (0.1 a 0.3$)$; mediana $(0.3$ a 0.7$)$; forte $(>0.7)$ e correlação perfeita (1). Todas as análises estatísticas foram realizadas através do software $\mathrm{SAS}^{\circledR}$.

Os resultados das análises de qualidade da água foram comparados aos valores estabelecidos pela Resolução do Conselho Nacional do Meio Ambiente (Conama) n. 357 de 17 de março de 2005 para corpos de água doce Classe 2 e salobra Classe 1. Entretanto, como o SEIA não dispõe das informações relativas às datas ou períodos em que as coletas foram realizadas, não foram procedidas análises correlacionadas à sazonalidade.

\section{RESULTADOS E DISCUSSÃO}

Analisados os dados, verifica-se que os valores de oxigênio dissolvido variaram de $0,1 \mathrm{mgL}^{-1} \mathrm{a}$ $9,96 \mathrm{mgL}^{-1}$ no rio Itanhém, de $3,47 \mathrm{mgL}^{-1}$ a $10,60 \mathrm{mgL}^{-1}$ no rio Jucuruçu e de $3,16 \mathrm{mgL}^{-1}$ a 8,41 $\mathrm{mgL}^{-1}$ no rio Peruípe (Tabela 4), em todos os casos com desvio padrão entre $\pm 1,2 \mathrm{mgL}^{-1}$ e $\pm 1,8$ $\mathrm{mgL}^{-1}$. O coeficiente de variação permaneceu em $20 \%$ para todos os pontos analisados e municípios, exceto para o ponto 3 , com coeficiente de variação igual a $35 \%$. Esses valores indicam que em todos os rios foram encontrados valores de oxigênio dissolvido inferiores a 5,0 $\mathrm{mgL}^{-1}$, valor mínimo permitido pela Resolução CONAMA N. ${ }^{\circ} 357$ de 2005. De acordo com Von Sperling (2014) [20] e Von-ahn e Pereira Filho (2015) [21], valores reduzidos de oxigênio dissolvido podem estar relacionados a diversos fatores, dentre eles o lançamento de despejos orgânicos nos mananciais de água, que ao serem degradados resultam no consumo de oxigênio dissolvido. A baixa concentração desse parâmetro é um grave problema pelo fato deste ser essencial à vida e crescimento de animais aquáticos como peixes [22], influenciando negativamente em comunidades que dependem da pesca para subsistência ou para a comercialização como Alcobaça, Prado e Nova Viçosa.

Outro parâmetro que apresentou valores elevados foi o de coliformes termotolerantes, variando entre 18,0 NMP/100mL e 16,000.0 NMP/100mL, tendo apresentado grande variação entre os pontos analisados, com os coeficientes de variação compreendidos entre $60 \%$ (ponto 3) e $248 \%$ (ponto 8). Portanto, está em desacordo com o determinado na Resolução CONAMA N. ${ }^{\circ} 357$ de 2005 que estabelece que tanto as águas doces Classe 2 quanto as águas salobras Classe 1 não devem apresentar valores de coliformes superiores a 1,000 NMP/100mL. Tal fato pode estar relacionado ao esgotamento sanitário inadequado dos municípios onde os rios Itanhém, Jucuruçu e Peruípe passam, uma vez que, de acordo com os dados disponibilizados no último senso realizado pelo Instituto Brasileiro de Geografia e Estatística (IBGE) [17], até 2010 a porcentagem de efluente sanitário tratado adequadamente nesses municípios eram de 31,7\% em Alcobaça, 55,3\% em Itamaraju, 66,1\% em Itanhém, 35,7\% em Jucuruçu, 35,3\% em Medeiros Neto, 18,3\% em Nova Viçosa, $14 \%$ em Prado, 75,9\% em Teixeira de Freitas e 30,4\% em Vereda. Esse fato, de acordo com Ayach et al. (2009) [23], possui influência direta na qualidade da água dos mananciais da região, uma vez que a principal contaminação dos rios se dá pelo lançamento inadequado de efluentes domésticos decorrentes do esgotamento sanitário ineficientes das áreas urbanas.

Cabe ressaltar, que das estações de monitoramento levantadas, as que apresentaram maior percentual de contaminação por coliformes termotolerantes foram as localizadas nas proximidades do município de Medeiros Neto, apresentando contaminação em 70,21\% das análises realizadas. Fato confirmado através da análise de variância desse parâmetro, onde os pontos 2 e 3 apresentaram médias altas: $3.512,4 \mathrm{NMP} / 100 \mathrm{~mL}$ e $10.004,5 \mathrm{NMP} / 100 \mathrm{~mL}$, respectivamente, sendo o ponto 3 , responsável pela maior média entre todos os pontos analisados.

O município de Jucuruçu apresentava, em 2010, 35,7\% de esgotamento sanitário adequado, o que sugere que tal cenário de degradação pode estar relacionado às conexões clandestinas de esgoto. 
Além disso, de acordo com informações relatadas no Plano Estadual de Manejo de Águas Pluviais e Esgotamento Sanitário da Bahia (PEMAPES) [18], o rio Itanhém, também conhecido como Alcobaça, recebe despejo de efluentes domésticos e industriais das cidades de Medeiros Neto e de Teixeira de Freitas, sendo que essa última conta com um pequeno distrito industrial. O PEMAPES reconhece que dos 14 municípios da Costa das Baleias, 10 deles lançam esgotos dos setores urbanos a céu aberto por meio de valas de descarte ou sarjetas de vias públicas que seguem para os corpos hídricos. Outro fator que pode ter influência direta nos altos valores de coliformes termotolerantes encontrados no rio Itanhém no trecho urbano de Medeiros Neto, é o ambiente degradado ao longo de toda a bacia, marcado pelo leito raso, assoreado, com perda de mata ciliar, o que pode proporcionar uma menor diluição e altos índices de coliformes termotolerantes [24]. Os mesmos autores ainda, destacam sinais de eutrofização na área urbana do rio.

A contaminação por coliformes termotolerantes é representada especialmente pela bactéria Escherichia coli disponível em animais homotérmicos, sendo uma água consumível apenas a que conta com reduzida contaminação microbiológica [25]. O número de coliformes termotolerantes em um corpo hídrico é um forte indício de contaminação recente, que é oriunda principalmente de despejo de esgoto doméstico, mas também da presença de animais próximos às margens do manancial. Coliformes é um parâmetro que atua como indicador de poluição fecal, pois estão sempre presentes no trato intestinal humano e de outros animais de sangue quente, sendo eliminadas em grandes números pelas fezes [26, 27].

Nesse contexto, vale destacar que a maior ocupação ao longo da bacia do Rio Itanhém é de pastagem, correspondente a $61,77 \%$ da área total, que se refere a aproximadamente $3.007,34 \mathrm{~km}^{2}$ de área (Tabela 3). Uma das principais atividades econômicas da região é a agropecuária, sendo possível que o gado nessa área tenha acesso livre ao rio (Tabela 3).

Tabela 3: Classes de uso e ocupação do solo em 2013 nas bacias dos rios Peruípe, Itanhém e Jucuruçu no estado da Bahia.

\begin{tabular}{ccccccc}
\hline \multirow{2}{*}{ Principais usos e ocupação } & \multicolumn{2}{c}{ Peruípe } & \multicolumn{2}{c}{ Itanhém } & \multicolumn{2}{c}{ Jucuruçu } \\
\cline { 2 - 7 } & $\mathbf{k m}^{\mathbf{2}}$ & $\mathbf{\%}$ & $\mathbf{k m}^{\mathbf{2}}$ & $\mathbf{\%}$ & $\mathbf{k m}^{\mathbf{2}}$ & $\mathbf{\%}$ \\
\hline Agricultura & 338,07 & 6,04 & 117,12 & 2,41 & 204,39 & 3,90 \\
Eucalipto & 2.053 & 36,70 & 674,72 & 13,86 & 119,34 & 2,28 \\
Pastagem & $1.407,10$ & 25,15 & $3.007,34$ & 61,77 & $3.119,94$ & 59,54 \\
Vegetação florestal & $1.137,60$ & 20,33 & 849,11 & 17,44 & $1.481,57$ & 28,28 \\
\hline
\end{tabular}

Fonte: Bahia (2016) [19].

Cenário similar ao encontrado nos rios analisados foi constatado no estudo realizado por Oliveira et al. (2017) [28], na bacia hidrográfica Cachoeirinha Invernada, localizada na cidade de Guarulhos, em São Paulo, onde comprovou-se que em áreas cercadas pelo desenvolvimento urbano há uma maior degradação na qualidade da água, principalmente no que se refere ao lançamento de efluente e à ineficiência do sistema de esgotamento sanitário.

Paralela à presença de coliformes termotolerantes em diversas campanhas de monitoramento, a inadequação e/ou inexistência de esgotamento sanitário e a ocupação do solo da região por pastagem, em diversos pontos por onde os rios que foram submetidos a análise passam, notam-se inadequações nos valores de fósforo total. Esse parâmetro apresentou valores entre $0,02 \mathrm{mg} / \mathrm{L}$ e $0,37 \pm 0,04 \mathrm{mg} / \mathrm{L}$ e coeficiente de variação médio igual a $72 \%$. De acordo com Esteves (1998) [29], o Fósforo Total é um parâmetro limitante da produtividade primária dos ecossistemas aquáticos, podendo ter origem natural, das rochas que compõem a bacia de drenagem e de materiais particulados na atmosfera, e antrópica, de efluentes domésticos, efluentes industriais e lixiviação do solo, sendo um dos principais responsáveis pela eutrofização dos mananciais.

Além disso, de acordo com Bahia (2016) [19], a porcentagem da área das bacias compostas por monocultura é de $67,89 \%$ na bacia do rio Peruípe, $78,04 \%$ na bacia do rio Itanhém e $65,72 \%$ na bacia do rio Jucuruçu, o que apresenta influência direta na lixiviação do solo e consequentemente no aporte de nutrientes nos corpos de água em questão. Este fato também demonstra que para o ano avaliado, a lei $\mathrm{N}^{\circ} 12.651$, de 25 de maio de 2012 [30], que estabelece o conceito de Área de Preservação Permanente (APP), que possui como uma das funções a preservação dos recursos 
hídricos, bem como, indica a implantação de vegetação nativa nas faixas marginais, não estava sendo efetivada nos perímetros das bacias.

Os valores de fósforo e os valores elevados de amônia, de acordo com a Empresa Brasileira de Pesquisa Agropecuária (2002) [31], também estão diretamente relacionados com o lançamento de efluentes e o uso e ocupação do solo das bacias, sendo a lixiviação do solo e o consequente carreamento de defensivos agrícolas uma de suas principais fontes. Sampaio et al. (2019) [32] citam que além destas relações, a elevação tanto do potencial hidrogeniônico, quanto de temperatura modificam o equilíbrio químico da amônia.

Outros parâmetros que também apresentaram valores discrepantes ao legislado foram sólidos totais dissolvidos e turbidez. De acordo com Quevedo e Paganini (2011) [33], além de influenciar nos valores de fósforo, o lançamento de efluentes domésticos e industriais e a lixiviação do solo, têm ligação direta com o aporte de sólidos totais dissolvidos no leito do rio e contribuem também para o aumento da turbidez. Logo, acredita-se que tais fatores tenham influenciado diretamente nas concentrações destes elementos na água.

Os valores do potencial hidrogeniônico variaram entre 3,63 e 9,96 $\pm 0,71$, com pouca variação de média entre os pontos, sendo 7,09 (ponto 1) e 6,62 (ponto 4), o que de acordo com Carvalho et al. (2015) [34] indicam a incapacidade de autodepuração dos mananciais, podendo estar relacionado à vazão reduzida e/ou ao lançamento de efluente e lixiviação do solo em quantidade superior à capacidade do manancial em diluir. Deste modo, quanto menores as vazões, maiores as concentrações de matéria orgânica, diminuindo os valores do potencial hidrogeniônico. De acordo com o mesmo autor, a tendência à acidez está associada à deterioração da matéria orgânica. Como os municípios presentes nas bacias hidrográficas em questão não apresentam um sistema de esgotamento sanitário que atenda à todas as comunidades, parte deste provavelmente é lançada nos cursos de água que cortam os municípios, o que contribui para o aumento da matéria orgânica nos mesmos. Segundo a Portaria ${ }^{\circ}$ 05, de 28 de setembro de 2017, desenvolvida pelo Ministério da Saúde [35], para que a água seja consumida pela população, recomenda-se que os valores de $\mathrm{pH}$ se mantenham no intervalo de 6 a 9,5, o que destoa do resultado mínimo encontrado na aferição.

Segundo Costa (2008) [36], o IQA é uma das principais formas de verificação de possíveis emissões irregulares e uso indevido dos corpos d'água, sendo a sua determinação realizada a partir de parâmetros como a variação da temperatura, potencial hidrogeniônico, oxigênio dissolvido, demanda bioquímica de oxigênio, coliformes termotolerantes, nitrato, fósforo total, turbidez e sólidos totais dissolvidos; podendo-se então chegar a uma conclusão da situação real daquele meio. Os resultados encontrados através das medições realizadas durante o período de monitoramento, apresentados na Figura 2, mostram que os rios Itanhém (1 a 6), Jucuruçu (7 a 11) e Peruípe (12), encontram-se com boa qualidade (entre 56,3 e 72,1 $\pm 7,66$ ) [20]. Isso reforça o afirmado anteriormente, de que as contribuições urbanas (efluente doméstico e efluentes industriais) e rurais, (lixiviação, erosão, escoamento superficial) têm contribuído diretamente para a sua atual situação.

Resultado similar foi encontrado por Şener et al. (2017) [37], no rio Aksu na Turquia, onde foi constatada através da análise de parâmetros físicos, químicos, biológicos e microbiológicos, determinados a partir de recomendações da Organização Mundial de Saúde, de legislações turcas e do IQA, que a qualidade da água da bacia em alguns pontos chega a ser "pobre" e "muito fraca", estando diretamente relacionada ao lançamento inadequado de efluentes em diversos pontos da bacia. 


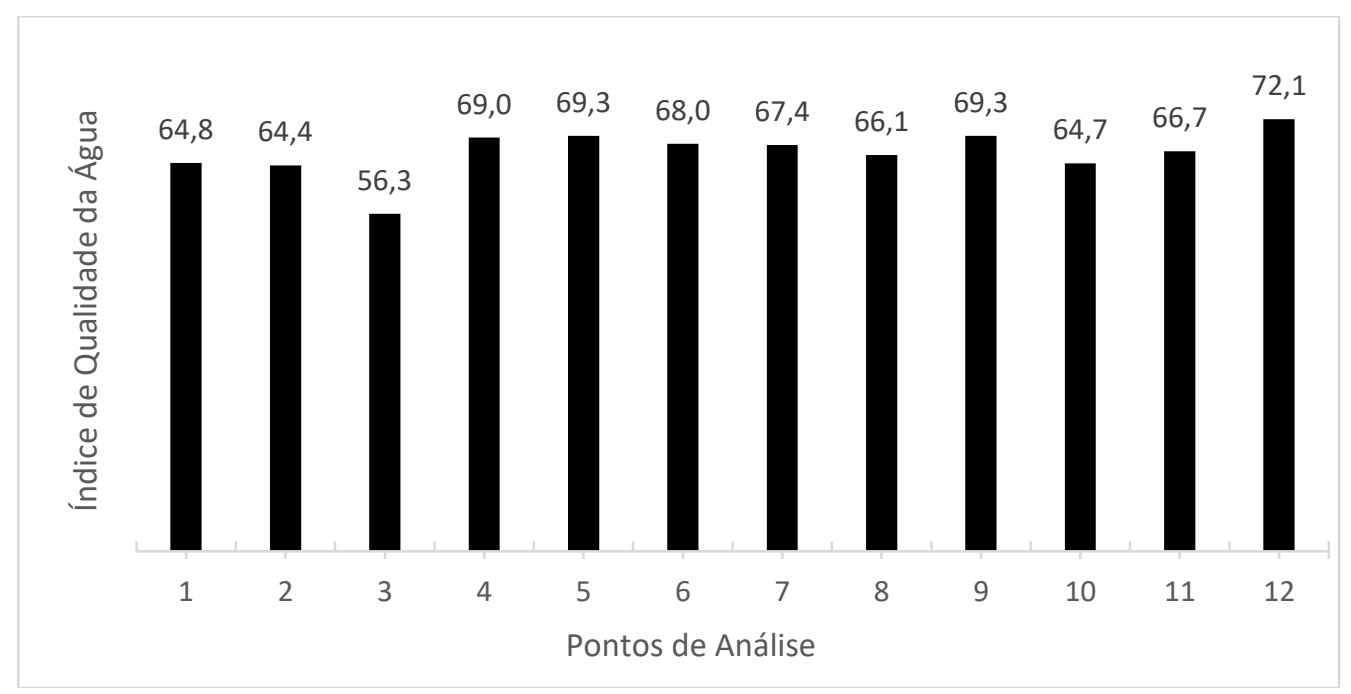

Figura 2: Índice de Qualidade da Água para os 12 pontos analisados nos rios Itanhém, Peruípe e Jucuruçu no estado da Bahia.

Ocorreu correlação negativa forte entre o IQA e o parâmetro coliformes termotolerantes; e houve a ocorrência de correlação positiva mediana entre o IQA e o parâmetro oxigênio dissolvido. Esse fato indica que a medida em que os valores de coliformes termotolerantes aumentam no curso de água o índice de qualidade da água diminui. Em contrapartida à medida em que o oxigênio dissolvido aumenta, o índice de qualidade da água também aumenta, indicando que uma menor quantidade de despejos orgânicos está sendo depositada no corpo hídrico (Tabela 4).

Outras correlações positivas fortes ocorreram entre sólidos totais dissolvidos e sólidos totais com alcalinidade e salinidade, sendo que o aumento dos níveis dos primeiros parâmetros gera consequentemente o aumento dos níveis dos segundos parâmetros nos cursos hídricos dos mananciais analisados. Além disso, ocorreu correlação direta entre esses parâmetros, sendo que o aumento de sólidos totais dissolvidos resulta no aumento de sólidos totais, e o aumento da Alcalinidade resulta no aumento da Salinidade, ou o contrário.

Os parâmetros sólidos totais dissolvidos e sólidos totais, também apresentaram correlação positiva de natureza mediana com o parâmetro demanda bioquímica de oxigênio e esse, por sua vez, apresentou correlação mediana com o parâmetro amônia. As demais correlações foram consideradas fracas. 
Tabela 4: Correlação de Spearman para os parâmetros da qualidade da água analisados.

\begin{tabular}{|c|c|c|c|c|c|c|c|c|c|c|c|c|c|c|c|c|c|c|}
\hline & 1 & 2 & 3 & 4 & 5 & 6 & 7 & 8 & 9 & 10 & 11 & 12 & 13 & 14 & 15 & 16 & 17 & 18 \\
\hline 1 & 1.00 & & & & & & & & & & & & & & & & & \\
\hline 2 & -0.72 & 1.00 & & & & & & & & & & & & & & & & \\
\hline 3 & -0.06 & -0.16 & 1.00 & & & & & & & & & & & & & & & \\
\hline 4 & 0.08 & -0.10 & 0.31 & 1.00 & & & & & & & & & & & & & & \\
\hline 5 & -0.04 & -0.09 & 0.28 & 0.02 & 1.00 & & & & & & & & & & & & & \\
\hline 6 & -0.24 & -0.09 & 0.09 & -0.04 & -0.03 & 1.00 & & & & & & & & & & & & \\
\hline 7 & -0.26 & -0.05 & 0.06 & -0.02 & -0.07 & 0.95 & 1.00 & & & & & & & & & & & \\
\hline 8 & -0.25 & 0.05 & 0.24 & 0.17 & 0.17 & -0.02 & -0.10 & 1.00 & & & & & & & & & & \\
\hline 9 & -0.14 & -0.08 & 0.05 & -0.13 & -0.23 & 0.80 & 0.81 & -0.23 & 1.00 & & & & & & & & & \\
\hline 10 & 0.24 & -0.02 & -0.08 & 0.17 & -0.04 & -0.16 & -0.17 & 0.09 & -0.14 & 1.00 & & & & & & & & \\
\hline 11 & -0.10 & 0.00 & 0.02 & 0.03 & -0.02 & 0.08 & 0.11 & -0.05 & 0.08 & -0.07 & 1.00 & & & & & & & \\
\hline 12 & 0.10 & -0.07 & -0.17 & 0.00 & -0.45 & 0.12 & 0.16 & -0.20 & 0.16 & -0.07 & 0.24 & 1.00 & & & & & & \\
\hline 13 & -0.17 & -0.03 & 0.17 & 0.22 & 0.29 & 0.23 & 0.24 & 0.32 & 0.00 & 0.07 & 0.11 & 0.10 & 1.00 & & & & & \\
\hline 14 & 0.41 & 0.01 & -0.25 & -0.15 & -0.15 & -0.22 & -0.20 & -0.12 & -0.07 & 0.15 & 0.04 & 0.10 & -0.06 & 1.00 & & & & \\
\hline 15 & -0.13 & -0.07 & 0.16 & 0.07 & 0.11 & 0.73 & 0.71 & -0.14 & 0.59 & -0.05 & 0.08 & 0.15 & 0.24 & -0.16 & 1.00 & & & \\
\hline 16 & -0.18 & 0.04 & 0.08 & 0.06 & -0.17 & 0.16 & 0.18 & -0.06 & 0.22 & -0.21 & 0.20 & 0.03 & -0.05 & -0.02 & 0.07 & 1.00 & & \\
\hline 17 & -0.10 & -0.13 & 0.08 & -0.16 & 0.29 & 0.38 & 0.38 & 0.11 & 0.27 & -0.14 & 0.20 & 0.05 & 0.25 & -0.11 & 0.35 & 0.12 & 1.00 & \\
\hline 18 & -0.05 & 0.04 & -0.05 & -0.19 & 0.05 & 0.07 & 0.12 & -0.06 & 0.21 & -0.11 & 0.17 & 0.07 & -0.03 & 0.12 & 0.03 & 0.37 & 0.20 & 1.00 \\
\hline
\end{tabular}

Em que: 1-IQA; 2-Coliformes Termotolerantes; 3-Clorofila- $a$; 4-Temperatura; 5-Sólidos Suspensos; 6-Sólidos Totais; 7-Sólidos Totais Dissolvidos; 8-Turbidez; 9-Salinidade; 10-Potencial Hidrogeniônico; 11-Nitrogênio Total; 12-Nitrato; 13-Fósforo Total; 14-Oxigênio Dissolvido; 15-Alcalinidade; 16-Demanda Bioquímica de Oxigênio; 17-Demanda Química de Oxigênio; 18-Amônia.

Dentre os pontos avaliados, o ponto 3 localizado em Medeiros Neto demonstra-se com maior quantidade de contaminação por coliformes termotolerantes e menor qualidade da água, como comprovado pela correlação, se destacando como área com urgente necessidade de intervenção a respeito do lançamento de poluentes e tratamento da água. Ainda assim, medidas intervencionistas devem ser tomadas em toda a região das bacias investigadas, por não terem apresentado alguns valores aceitáveis, de acordo com o preconizado pela Resolução Conama n. ${ }^{\circ}$ 357/2005 nos parâmetros de sólidos totais dissolvidos, turbidez, oxigênio dissolvido, coliformes termotolerantes, fósforo total, amônia e potencial hidrogeniônico, apesar da boa qualidade demonstrada pelo IQA.

Sabe-se que o consumo de água não tratada, e com valores discrepantes dos legislados pode gerar inúmeras complicações relacionadas à saúde da população, por meio de doenças de veiculação hídrica, e isto está ligado principalmente a falta de serviços de saneamento básico nos municípios [38]. A realidade de transformação do ambiente, do despejo de efluentes, e do uso e ocupação de áreas próximas aos rios do extremo sul baiano, como o rio Itanhém [39], três corpos hídricos do município de Teixeira de Freitas [40] e os rios Jardim e Mutari [41] já demonstram que em paralelo à degradação ambiental e urbanização, existe um comprometimento da qualidade hídrica.

Todos os anos várias mortes humanas ocorrem no planeta, além de toda a perda de biodiversidade, em detrimento da qualidade inaceitável de parâmetros da água [42]. Como medidas de mitigação e melhoria da qualidade da água, para o caso dos rios estudados, podem ser listadas ações que sanem as contaminações como: incialmente, a implantação de políticas públicas municipais voltadas ao tratamento correto e adequado de esgoto, em sinergia com práticas de educação ambiental e saúde [43], coleta e descarte de resíduos em local e condições de manutenção apropriadas [44], intervenção direta na forma como as atividades econômicas predominantes estão sendo desenvolvidas e fiscalização de como o entorno dos rios está sendo ocupado, para que seja permitida a perpetuação das funções eco-hidrológicas fornecidas pela floresta nativa, conforme 0 novo Código Florestal, Lei Federal n 12.561/12 [30, 45]. 


\section{CONCLUSÃO}

$\mathrm{Na}$ avaliação, como um todo, dos parâmetros físicos, químicos e microbiológicos, nas bacias dos rios Itanhém, Jucuruçu e Peruípe, no período entre 2009 e 2019, foi possível inferir que tais bacias se encontram fora dos padrões determinados pela Resolução Conama n..$^{\circ} 357$ de 2015, tanto para as águas doces Classe 2 quanto às águas salobras Classe 1, devido principalmente à influência significativa da atividade humana rural e urbana nessa área. Apesar disso, os resultados do IQA indicam que suas águas podem ser classificadas com uma qualidade boa. Entretanto, o fato de existirem parâmetros relevantes fora do padrão legislado, aduz que as comunidades que usufruem dessas bacias podem estar com a saúde, a qualidade de vida e subsistência em risco. Logo, concluise que a poluição e contaminação desses mananciais podem ser mitigadas através de ações do poder público que visem minimizar os impactos causados pela descarga de efluentes nestes corpos hídricos, pois os municípios localizados na região não apresentam um sistema de esgotamento sanitário que atenda a todos. Cabe ressaltar também, a importância de se investir em ações voltadas à educação ambiental da população, principalmente das comunidades ribeirinhas, visto que o município de Medeiros Neto, que em 2010 possuía 35,3\% de esgotamento sanitário adequado, apresentou contaminação por Coliformes Termotolerantes em 70,21\% das análises realizadas entre os anos de 2009-2019, o que pode ser um indicativo da presença de ligações clandestinas de esgoto e um alerta de que pode não ter ocorrido melhorias no saneamento básico da população ao longo desse período.

\section{REFERÊNCIAS BIBLIOGRÁFICAS}

1. Peixoto JS. Monitoramento da qualidade da água no baixo São Francisco e ações de educação ambiental [dissertação]. São Cristóvão (SE): Universidade Federal de Sergipe; 2016. 87 p.

2. Souza CL, Andrade CS. Health, environment and territory: a necessary discussion in health training. Ci Saúde Coletiva. 2014 Out;19(10):4113-4122, doi: 10.1590/1413812320141910.08992014.

3. Arruda GB, Correia KV, Oliveira RS, Brainer NJE, Araújo FP, Carneiro KWF. Análise da qualidade da água do riacho Moraes em área influenciada pela produção de gesso no município de Araripina, PE Brasil. Rev Geologia. 2015 Mai;28(1):27-38.

4. Ponsadailakshmi S, Sankari SG, Prasanna SM, Madhurambal G. Evaluation of water quality suitability for drinking using drinking water quality index in Nagapattinam district, Tamil Nadu in Southern India. Groundwater Sustain Develop. 2018 Mar;6:43-49, doi: 10.1016/j.gsd.2017.10.005.

5. Lopes FW, Júnior AP. Influência das condições naturais de $\mathrm{pH}$ sobre o índice de qualidade das águas (IQA) na bacia do Ribeirão de Carrancas. R Geografias. 2010 Dez;6(2):134-147.

6. Souza JR, Moras ME, Sonoda SL, Santos HC. A importância da qualidade da água e os seus múltiplos usos: caso Rio Almada, sul da Bahia, Brasil. Rev Eletr Prodema. 2014 Abr;8(1)26-45.

7. Brasil. Presidência da República. Lei n. ${ }^{\circ}$ 9.433, de 08 de janeiro de 1997. Brasília, DF, 08 de jan. de 1997.

8. Conselho Nacional de Meio Ambiente. Resolução Conama n. ${ }^{\circ} 274$, de 29 de novembro de 2000. Brasília: Ministério do Meio Ambiente, Conselho Nacional de Meio Ambiente (CONAMA). 2000.

9. Conselho Nacional de Meio Ambiente. Resolução Conama n. ${ }^{\circ}$ 357, de 17 de março de 2005. Brasília: Ministério do Meio Ambiente, Conselho Nacional de Meio Ambiente (CONAMA). 2005.

10. Conselho Nacional de Meio Ambiente. Resolução Conama n. ${ }^{\circ}$ 396, de 03 de abril de 2008. Brasília: Ministério do Meio Ambiente, Conselho Nacional de Meio Ambiente (CONAMA). 2008.

11. Conselho Nacional de Meio Ambiente. Resolução Conama n. ${ }^{\circ}$ 430, de 13 de maio de 2011. Brasília: Ministério do Meio Ambiente, Conselho Nacional de Meio Ambiente (CONAMA). 2011.

12. Associação Brasileira de Normas Técnicas. NBR 12212: Projeto de poços para captação subterrânea. Rio de Janeiro, 1992.

13. Associação Brasileira de Normas Técnicas. NBR 12244: Construção de poços para captação subterrânea. Rio de Janeiro, 1992.

14. ANA - Agência Nacional de Águas. Indicadores de Qualidade - Índice de Qualidade das Águas (IQA) [Internet]. Gestão da Água [citado em 2019]. Disponível em: <http://pnqa.ana.gov.br/indicadores-indiceaguas.aspx>. Acesso em: 12 nov. 2019.

15. _. Rios. [Internet]. Gestão da Água [citado em 2019]. Disponível em: <https://www.ana.gov.br/gestao-da-agua/saiba-quem-regula/rios/rios>. Acesso em: 12 nov. 2019.

16. INEMA - Instituto do meio ambiente e recursos hídricos. CBH Peruípe, Itanhém e Jucuruçu [Internet]. Salvador: Estado da Bahia. Disponível em: <http://www.inema.ba.gov.br/gestao-2/comites-debacias/comites/cbh-peruipe-itanhem-e-jucurucu/>. Acesso em: 12 nov. 2019. 
17. IBGE - Instituto Brasileiro de Geografia e Estatística. Panorama [Internet]. Disponível em: < https://cidades.ibge.gov.br/ >. Acesso em: 25 nov. 2019.

18. BAHIA, 2011. Plano Estadual de Manejo de Águas Pluviais e Esgotamento Sanitário da Bahia PEMAPES. TOMO IX. Diagnostico e Levantamentos. V. 5, RDS 7 Costa das Baleias. Secretaria de Desenvolvimento Urbano - SEDUR. Disponível em: <http://www.sihs.ba.gov.br/arquivos/File/RDS07CostaBaleias.pdf>. Acesso em 25 nov. 2019.

19. BAHIA, 2016. Plano Territorial De Desenvolvimento Sustentável e Solidário do Extremo Sul da Bahia. Governo do Estado da Bahia: Secretaria de Planejamento. Disponível em: < encurtador.com.br/qvIT2>. Acesso em: 25 nov. 2019.

20. Von Sperling M. Introdução à qualidade das águas e ao tratamento de esgotos. 4. ed. Belo Horizonte: DESA/UFMG; 2014. 470 p.

21. Von-Ahn CME, Pereira Filho J. Diagnóstico da qualidade de água ao longo do estuário do rui Itajaí-Aço, SC. Rev Bras Rec Hídr. 2015 Abr-Jun;20(2):331-342.

22.Zeni TO, Ostrensky A, Westphal GG. Respostas adaptativas de peixes a alterações ambientais de temperatura e de oxigênio dissolvido. Arch Vet Sci. 2016 Ago;21(3):1-16, doi: 10.5380/avs.v21i3.40165.

23. Ayach LR, Pinto AL, Cappi N, Guimarães ST. Contaminação das águas subterrâneas por coliformes: um estudo da cidade de Anastácio-MS. Climatologia e Estudos da Paisagem. 2009 Dez;4(1):5-26.

24. Sarmento-Soares LM, Mazzoni R, Martins-Pinheiro RF. A fauna de peixes na bacia do Rio Itanhém, leste de Minas Gerais e extremo Sul da Bahia. Pan-American J Aquatic Sci. 2010;5(1):47-61.

25. Lacerda AB, Räder AS; Lopes, ES. A eficiência de remoção de coliformes em uma estação de tratamento de água convencional/The efficiency of coliform removal in a conventional water treatment plant. Braz J Develop. 2019 Jun;5(6):7523-7359, doi: 10.34117/bjdv5n6-225.

26. Rodrigues JRDD, Jorge AOC, Ueno, M. Avaliação da qualidade das águas de duas áreas utilizadas para recreação do rio Piracuama-SP. Rev Biociências. 2009 Set;15(2): 88-94.

27. Companhia Ambiental do Estado de São Paulo - CETESB. Guia nacional de coleta e preservação de amostras: água, sedimento, comunidades aquáticas e efluentes líquidas. Brasília: CETESB/ANA; 2018. $327 \mathrm{p}$.

28. Oliveira IB, Negrão FI, Silva AGLS. Mapeamento dos aquíferos do estado da Bahia utilizando o Índice de Qualidade Natural das Águas Subterrâneas - IQNAS. Rev Águas Subterrâneas. 2007;21(1):123-137, doi: 10.14295/ras.v21i1.16176.

29. Esteves, F. Fundamentos da limnologia. 2. Ed. Rio de Janeiro: Interciência/FINEP; 1998. 790 p.

30. BRASIL. Portaria de Consolidação $n^{\circ}$ 5, de 28 de setembro de 2017. Diário Oficial [do Ministério da Saúde], Brasília, DF, 28 set. 2017.

31. Empresa Brasileira de Pesquisa Agropecuária (EMBRAPA). Agricultura e Qualidade da Água: Contaminação da Água por Nitrato. Planaltina: Embrapa Cerrados; 2002. 28 p.

32. Sampaio CA, Ide GM, Batalha CP, Pereira LC, Bueno LF. Análise técnica de água de fontes rurais. Eng Sanit Amb. 2019 Mar/Abr;24(2):213-217, doi: 10.1590/s1413-41522019116954.

33. Quevedo CMG, Paganini WS. Impactos das atividades humanas sobre a dinâmica do fósforo no meio ambiente e seus reflexos na saúde pública. Ci Saúde Coletiva. 2011 Ago;16(8):3529-3539, doi: 10.1590/S1413-81232011000900021.

34. Carvalho KQ, Lima SB, Passig FH, Gusmão LK, Souza DC, Kreutz C, Belini AD, Arantes EJ. Influence of urban area on the water quality of the Campo River basin, Paraná State, Brazil. Braz J Biol. 2015 Dez;75(4):96-106, doi: 10.1590/1519-6984.00413suppl.

35. BRASIL. Lei $\mathrm{n}^{\mathrm{o}} 2.914$, de 12 de dezembro de 2011. Dispõe sobre os procedimentos de controle e de vigilância da qualidade da água para consumo humano e seu padrão de potabilidade. Diário Oficial [da República Federativa do Brasil], Brasília, DF, 12 dez. 2011.

36. Costa ECTA. Diagnóstico ambiental das águas do estuário Jundiaí-Potengi pela determinação dos índices de qualidade da água e Toxidez [dissertação]. Natal (RN): Universidade Federal do Rio Grande do Norte; 2008. 135f.

37. Şener Ş, Şener E, Davraz A. Evaluation of water quality usingwater quality index (WQI)method and GIS in Aksu River (SW-Turkey). Sci Total Environm. 2015 Abr;584-585:131-144, doi: 10.1016/j.scitotenv.2017.01.102.

38. Rodrigues ÁL, Melo LP, Souza WB, Lima LC, Souza DC. Levantamento e análises das fontes alternativas de captação de água utilizadas no abastecimento de uma população rural de Visconde do Rio BrancoMG. Águas Subterrâneas. 2019;33(1):1-6, doi: 10.14295/ras.v33i1.29293.

39. Cunha AH, Tartler N, Santos RB, Fortuna JL. Análise microbiológica da água do rio Itanhém em Teixeira de Freitas-BA. Rev Biociências. 2010 Jul;16(2):86-93.

40. Matias MI, Santos JV, Freitas RM, Matias LC. Qualidade de corpos hídricos no extremo Sul da Bahia. Rev Verde Agroecol Desenv Sustent. 2018 Abr-Jun;13(2):235-240, doi: 10.18378/rvads.v13i2.5467. 
41. Bandeira MS, Santos LD, Silva CT, Bandeira ML. Impactos ambientais de rios com nascentes em unidade de conservação: avaliação preliminar dos rios Mutari e Jardim, Santa Cruz Cabrália, Bahia. Rev Gestão Sustent Amb. 2019 Jul-Set;8(3):389-417, doi: 10.19177/rgsa.v8e32019389-417.

42. Ribeiro LGG, Rolim ND. Planeta água de quem e para quem: uma análise da água doce enquanto direito fundamental e sua valoração mercadológica. Rev Direito Amb Soc. 2017;7(1):7-33.

43. Santos RF, Irazustra SP, Teixeira EP, Degasperi FT. Abordagem descentralizada para concepção de Sistemas de Tratamento de Esgoto Doméstico. Rev Eletr Tecnol Cultura. 2015 Abr;1(1):35-44.

44. Rosa BP, Paula BC, Coleone ES, Campos F. Impactos causados em cursos d'água por aterros controlados desativados no Município de São Paulo, Sudeste do Brasil. Rev Bras Gestão Amb Sustent. 2017 Jun;4(7):63-76, doi: 10.21438/rbgas.040707.

45. Tambosi LR, Vidal MM, Ferraz SF, Metzger JP. Funções eco-hidrológicas das florestas nativas e o Código Florestal. Estudos avançados. 2015 Mai/Ago;29(84):151-162, doi: 10.1590/S010340142015000200010. 